\title{
Proliferation and aneusomy predict survival of young patients with astrocytoma grade II
}

\section{PH Wessels*, , AHN Hopman ${ }^{2}$, B Kubat ${ }^{3}$, AGH Kessels ${ }^{4}$, EW Hoving ${ }^{5}$, MIJ Ummelen ${ }^{2}$, FCS Ramaekers ${ }^{2}$ and A Twijnstra}

'Department of Neurology, Research Institute Growth and Development (GROW), University Hospital Maastricht, The Netherlands; ${ }^{2}$ Department of Molecular Cell Biology, Research Institute Growth and Development (GROW), University Maastricht, The Netherlands; ${ }^{3}$ Department of Pathology, Research Institute Growth and Development (GROW), University Hospital Maastricht, The Netherlands; ${ }^{4}$ Department of Clinical Epidemiology, Research Institute Growth and Development (GROW), University Hospital Maastricht, The Netherlands; ${ }^{5}$ Department of Neurosurgery, University Hospital Groningen, The Netherlands

The clinical course of astrocytoma grade II (AII) is highly variable and not reflected by histological characteristics. As one of the best prognostic factors, higher age identifies rapid progressive A II. For patients over 35 years of age, an aggressive treatment is normally propagated. For patients under 35 years, there is no clear guidance for treatment choices, and therefore also the necessity of histopathological diagnosis is often questioned. We studied the additional prognostic value of the proliferation index and the detection of genetic aberrations for patients with A II. The tumour samples were obtained by stereotactic biopsy or tumour resection and divided into two age groups, that is $18-34$ years $(n=19)$ and $\geqslant 35$ years $(n=28)$. Factors tested included the proliferation (Ki-67) index, and numerical aberrations for chromosomes 1, 7, and 10, as detected by in situ hybridisation (ISH). The results show that age is a prognostic indicator when studied in the total patient group, with patients above 35 years showing a relatively poor prognosis. Increased proliferation index in the presence of aneusomy appears to identify a subgroup of patients with poor prognosis more accurately than predicted by proliferation index alone. We conclude that histologically classified cases of A II comprise a heterogeneous group of tumours with different biological and genetic constitution, which exhibit a highly variable clinical course. Immunostaining for Ki-67 in combination with the detection of aneusomy by ISH allows the identification of a subgroup of patients with rapidly progressive A II. This is an extra argument not to defer stereotactic biopsy in young patients with radiological suspicion of A II.

British Journal of Cancer (2003) 89, 128 -134. doi:I0.1038/sj.bjc.6601067 www.bjcancer.com (c) 2003 Cancer Research UK

Keywords: astrocytoma grade II; prognosis; proliferation; aneusomy; Ki-67 index; in situ hybridisation

Controversy exists with respect to optimal treatment protocols for lowgrade diffuse astrocytoma (astrocytoma WHO grade II; A II) because prospective studies comparing treatment strategies are rare (Karim et al, 1996; 2002; Shaw et al, 2002). Another reason for this controversy is that the interval after which malignant progression of A II occurs is difficult to predict. Clinical factors that may correlate with survival include those related to patient age, presenting symptoms, duration of symptoms, performance status, tumour volume, extent of resection, and timing and dose of radiotherapy (Berger et al, 1994; Lote et al, 1997). Patient age is the single consistent prognostic factor in these retrospective studies. Patient age under 35 years (Shaw et al, 1989; Arienti et al, 2001), or under 40 years in other series (Bauman et al, 1999) is often associated with a prolonged survival. Since the benefits of early treatment have to

\footnotetext{
*Correspondence: Dr PH Wessels, Department of Neurology, University Hospital Maastricht, PO Box 5800, 6202 AZ Maastricht, The Netherlands; E-mail: PWES@SNEU.AZM.NL

Supported by a grant from the Dutch Cancer Society and the Nijbakker Morra Foundation.

Received 4 December 2002; revised 24 March 2003; accepted 10 April 2003
}

be balanced against the possibility of long-term side effects from radiation therapy, patient age is decisive in current treatment protocols for A II. For patients under 35 years of age, the benefit of early and aggressive treatment has never been proven sufficiently and therefore treatment is often deferred (Vecht, 1993). As a result, in young patients also a controversy exists concerning the usefulness of an immediate histological diagnosis, involving stereotactic biopsy (Recht et al, 1992).

Ultimately the majority of A II progresses to high-grade astrocytomas (astrocytoma WHO grade III and grade IV; A III/A IV), which is characterised by an increase in proliferation activity and an accumulation of genetic abnormalities. Proliferation and cytogenetic markers may therefore identify rapid progressive A II. Increased proliferation activity correlates with shorter survival in most series of astrocytomas, although the number of A II was often too small for separate analyses (Sallinen et al, 1994; Korkolopoulou et al, 1997). Numerical chromosomal aberrations have been reported in astrocytomas, such as aneusomy 1 , trisomy 7 and monosomy 10 . It has been shown that trisomy 7 correlates with shorter survival of A II patients (Wessels et al, 2002).

In the underlying study, the prognostic value of the proliferation (Ki-67) index and the detection of numerical aberrations for 
chromosomes 1,7 , and 10 was evaluated. The correlation of ; these parameters with survival analysis was performed for patients aged 18-34 years and $\geqslant 35$ years to assess whether these parameters allow the identification of rapid progressive A II in young patients.

\section{MATERIALS AND METHODS}

\section{Patient material}

Tissue specimens from 47 adult patients diagnosed with supratentorial astrocytoma grade II were collected from the data files of the Departments of Pathology of the University Hospitals of Maastricht and Groningen, and the Atrium Hospital in Heerlen, The Netherlands. Histopathological revision according to the WHO classification (Kleihues and Cavenee, 2000) revealed 44 fibrillary astrocytomas and three gemistocytic astrocytomas (all WHO grade II). Astrocytomas with mitotic figures were not included in this series. In order to diminish the probability of sampling error A II in which the neuroradiologists suspected high-grade astrocytoma and which showed radiological characteristics for tumour bleeding as well as extensive contrast enhancement, were not included in this series. Patient records were examined with regard to the first neurological symptoms, radiological findings, neurosurgical procedure, dose and timing of radiotherapy, and survival interval.

Mean and median ages were respectively, 38 and 41 years (range, 18-69 years). The study included 22 women (47\%) and 25 men $(53 \%)$. Seizures were the most frequent presenting symptom (77\%), followed by focal neurological deficit (26\%), mental changes $(15 \%)$ and signs of raised intracranial pressure $(17 \%)$. The median duration of preoperative symptoms was 3 months (range: 1 week-157 months). Most tumours were located in the frontal (51\%) and temporal/parietal (45\%) lobes and less frequently in the occipital lobe $(4 \%)$. The majority of patients $(n=41)$ underwent neurosurgery immediately after coming for medical attention and had their first neuroimaging test. In six patients, neurosurgical intervention was extended for 36150 months. No association was found, using Pearson's correlation coefficient, between preoperative interval and proliferation index or chromosomal status. For this reason all cases were included in this study.

Neurosurgical procedures consisted of a biopsy in $29(62 \%)$ and resection in $18(38 \%)$ patients. Radiotherapy was given immediately postoperative in $28(60 \%)$ patients, delayed in 10 $(21 \%)$ patients, and nine $(19 \%)$ patients were still not irradiated at the last follow-up.

\section{Proliferation index: Ki-67 immunohistochemistry}

Paraffin sections (5- $\mu \mathrm{m}$ thick) were preincubated in methanol with $0.3 \% \mathrm{H}_{2} \mathrm{O}_{2}$. Tissues known to be negative and positive for $\mathrm{Ki}-67$ were used as controls. Antigen retrieval was achieved

by incubation with $10 \mathrm{~mm}$ citrate buffer ( $\mathrm{pH}$ 6.0) in a domestic microwave oven at $700 \mathrm{~W}$ for $10 \mathrm{~min}$. The sections were incubated with the mouse monoclonal antibody MIB-1 directed against Ki-67 (Immunotech S.A., Marseille, France) at a $1: 12$ solution in PBS containing 4\% normal goat serum for $60 \mathrm{~min}$. Subsequently, biotin-labelled horse anti-mouse antibody at a 1:200 dilution and avidin-biotin peroxidase complex (Vector Laboratories, Burlingame, CA, USA) were applied for 60 and $45 \mathrm{~min}$, respectively. Peroxidase activity was detected using diaminobenzidine in PBS/ imidazol buffer with $0.02 \%$ $\mathrm{H}_{2} \mathrm{O}_{2}$. Nuclei were scored for positivity in 500 cells in each sample in the areas with highest immunopositivity. The mean proliferation (Ki-67) index was $2.7 \%$ (range $0.0-9.2 \%$ ).
Detection of numerical chromosomal aberrations by in situ hybridisation (ISH)

In situ hybridisation was performed as described earlier (Hopman and Ramaekers, 1998). Paraffin sections (5- $\mu \mathrm{m}$ thick) were deparaffinised and pretreated in $85 \%$ formic acid/0.3\% $\mathrm{H}_{2} \mathrm{O}_{2}$ for $20 \mathrm{~min}$. Thereafter the slides were incubated in $1 \mathrm{M}$ sodium-thiocyanate at $80^{\circ} \mathrm{C}$ for $10 \mathrm{~min}$. Subsequently, proteolytic digestion was performed by $4 \mathrm{mg} \mathrm{ml}^{-1}$ pepsin (Sigma Chemical Co, St Louis, MO, USA) for $10 \mathrm{~min}$ at $37^{\circ} \mathrm{C}$ in $0.02 \mathrm{M} \mathrm{HCl}$. Then the slides were fixed in $1 \%$ formaldehyde in phosphate-buffered saline (PBS) for $15 \mathrm{~min}$, and rinsed in PBS and double distilled water.

The biotin-labelled DNA probes used in this study were specific for the centromeric regions of chromosome 1 (1q12, pUC 1.77) and chromosome 10 (D10Z1), and the alphoid region of chromosome 7 ( $\mathrm{p} 7 \mathrm{t} 1)$. The probes were hybridised to the target-DNA in a mixture containing $2 \times$ standard saline citrate (SSC), $60 \%$ formamide, $10 \%$ dextran sulphate, and $0.2 \mathrm{mg} \mathrm{ml}^{-1}$ herring sperm DNA. After denaturation at $80^{\circ} \mathrm{C}$ for $5 \mathrm{~min}$, the slides were incubated overnight at $37^{\circ} \mathrm{C}$. Subsequently, the slides were washed twice in $2 \times \mathrm{SSC} / 0.05 \%$ Tween at $45^{\circ} \mathrm{C}$, and in four $\times$ SSC $/ 0.05 \%$ Tween at room temperature. To detect probe hybridisation, the slides were incubated for $30 \mathrm{~min}$ at room temperature with mouse-antibiotin monoclonal antibody, followed by biotinylated horse-anti-mouse, and finally with the avidinbiotin-peroxidase complex (Vector Laboratories, Burlingame, CA, USA). Finally, $0.1 \mathrm{~m}$ diaminobenzidine (Sigma) in PBS containing $0.03 \% \mathrm{H}_{2} \mathrm{O}_{2}$ was applied for visualisation of the peroxides' activity. To improve identification of the individual nuclei, bright-field microscopy was combined with fluorescent nuclear counterstaining using 4,6-diamino-phenylindol (DAPI, Sigma). The samples were evaluated with a Leica DMBRE microscope (Leica Mikroskopie \& Systeme GmbH, Wetzlar, Germany). The number of signals per nucleus was counted in at least 200 nonoverlapping nuclei. Trisomy/polysomy (gain) was defined as $>5 \%$ of nuclei containing three or more signals, and monosomy (loss) as $>25 \%$ of nuclei with none or one signal per nucleus. The tumours were classified as aneusomic when gain or loss of at least one of the chromosomes was detected. The other A II were classified disomic. As detected by ISH, 32 (68\%) of the tumours showed aneusomy for one or more of the chromosomes investigated. The most frequent aberration was aneusomy for chromosome 7 in 31 (66\%) of A II. Aneusomy for chromosome 1 was detected in 24 (51\%) and aneusomy for chromosome 10 in 25 (53\%) of the samples. Monosomy 10 was only detected in two samples (4\%), which also showed trisomy/polysomy 7 . The data of the individual chromosomes are described in detail elsewhere (Wessels et al, 2002).

\section{Statistical analyses}

The following factors were considered as possible prognostic parameters for survival: patient age, sex, presenting symptoms, preoperative duration of symptoms, tumour location, neurosurgical procedure, timing of radiotherapy, proliferation index, and chromosomal status.

The. influence of these factors on survival was tested by univariate analysis using log-rank tests. Possible prognostic factors from the univariate analyses with $P$-values less than 0.10 (according to recommendation in the literature (Hosmer and Lemeshow, 2000)) were entered into the multivariate analyses using a forward stepwise method in order to identify independent prognostic parameters (Cox, 1972). Univariate and multivariate associations between factors and survival were assessed using a Cox regression model. Subsequently, tumour-related factors were used for analysis in age-stratified groups. 


\section{RESULTS}

The median survival interval for patients with astrocytoma grade II as estimated by the Kaplan-Meier method was 90 months (95\% confidence interval 72-108 months). When determining the influence of age on the period of survival after the first diagnosis of A II, it becomes obvious that the group aged $\geqslant 35$ years at the time of diagnosis exhibits a significantly shorter survival period as compared to the 18-34 year-old patient group (Figure 1; log-rank; $P$-value $=0.05)$. Other factors significantly associated with shorter survival were focal neurological deficit at presentation, proliferation (Ki-67) index $>1 \%$, and aneusomy. Upon multivariate analysis proliferation index $>1 \%$, patient age $\geqslant 35$ years, and aneusomy were independently correlated with shorter survival (Table 1).

To investigate the interactions between the proliferation index and aneusomy with age, we analysed the influence of these two factors on survival stratified for age. When correlating the proliferation index to survival in the two age groups separately, it appears that in the group of 18-34-year-old patients, a clearcut distinction can be made between those with a proliferation index $\leqslant 1 \%$, showing long-term survival, and those with a proliferation index $>1 \%$, showing more progressive AII (Figure 2A; log-rank; $P$-value $=0.02)$. Also in the $\geqslant 35$-year-old patients, the prolifera-

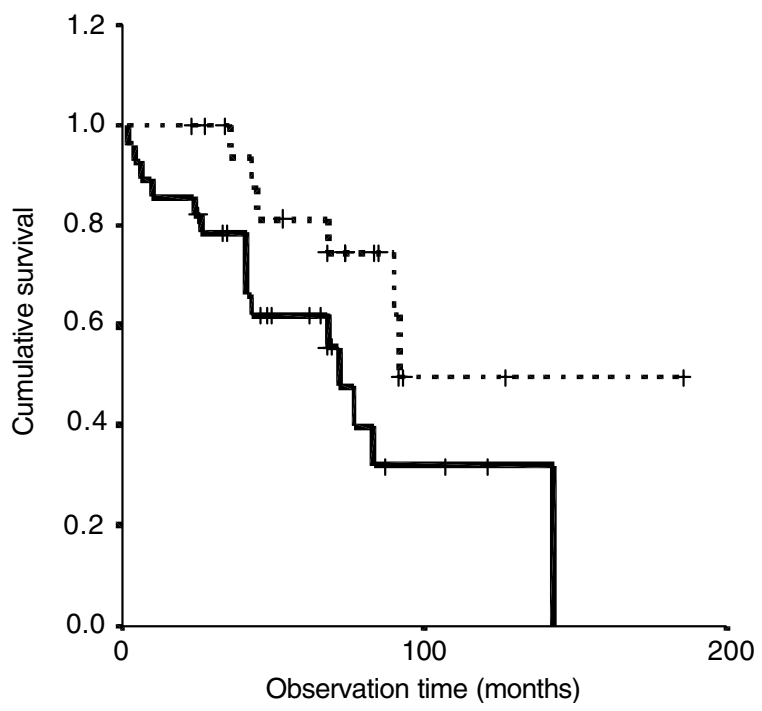

Figure I Association between patient age (18-34 vs $\geqslant 35$ years) and survival in A II. Kaplan-Meier, P-value $=0.05$, log-rank. . . . . . . . $18-34$ years $(n=19)$. $\geq 35$ years $(n=28)$.

Table I Unfavourable prognostic factors for patients with astrocytoma grade II

\begin{tabular}{lcc}
\hline Parameter & Hazard ratio $(\mathbf{9 5 \%} \mathbf{C I})^{\mathbf{a}}$ & P-value \\
\hline Univariate analysis & $3.63(1.22-10.82)$ & \\
Proliferation index $>1 \%(n=29)$ & $2.78(1.12-6.90)$ & 0.02 \\
Focal neurological deficit $(n=13)$ & $3.29(0.97-11.20)$ & 0.03 \\
Aneusomy $(n=32)$ & $2.52(0.97-6.58)$ & 0.06 \\
Patient age $\geqslant 35$ years $(n=28)$ & & 0.06 \\
Multivariate analysis & $4.81(1.50-15.38)$ & \\
Proliferation index $>1 \%(n=29)$ & $3.01(1.13-7.99)$ & 0.01 \\
Patient age $\geqslant 35$ years $(n=28)$ & $3.66(1.06-12.62)$ & 0.03 \\
Aneusomy $(n=32)$ & & 0.04 \\
\hline
\end{tabular}

${ }^{\mathrm{a}} \mathrm{Cl}=$ confidence interval. tion index proved to have additional prognostic value, although less apparent as compared to the younger group (Figure 2B; $P$-value $=0.03$ ).

Using the ISH protocol with probes for chromosomes 1,7, and 10 , cases of A II with an apparently normal (disomic) chromosomal content can be separated from aneusomic cases. In the whole group of patients with A II the detection of aneusomy has additional value in distinguishing between rapid and slow progressive A II. In the stratified age groups an aberrant chromosomal constitution is not associated with shorter survival in both the 18-34-year-old (Figure $3 \mathrm{~A} ; P$-value $=0.36$ ) and the $\geqslant 35$-year-old (Figure 3B; $P$-value $=0.09$ ) groups.

However, the combination of a high proliferation index and aneusomy very accurately identified patients with an unfavourable outcome in both the 18-34-year-old (Figure 4A; $P$-value $=0.01$ ) and the $\geqslant 35$-year-old patient groups (Figure $4 \mathrm{~B} ; P$-value $=0.001$ ) The combination of both factors reclassified three $(27 \%)$ of 11 patients of 18-34 years into the group with relatively good prognosis (compare Figures $4 \mathrm{~A}$ to $2 \mathrm{~A}$ ). In five of 18 patients in the
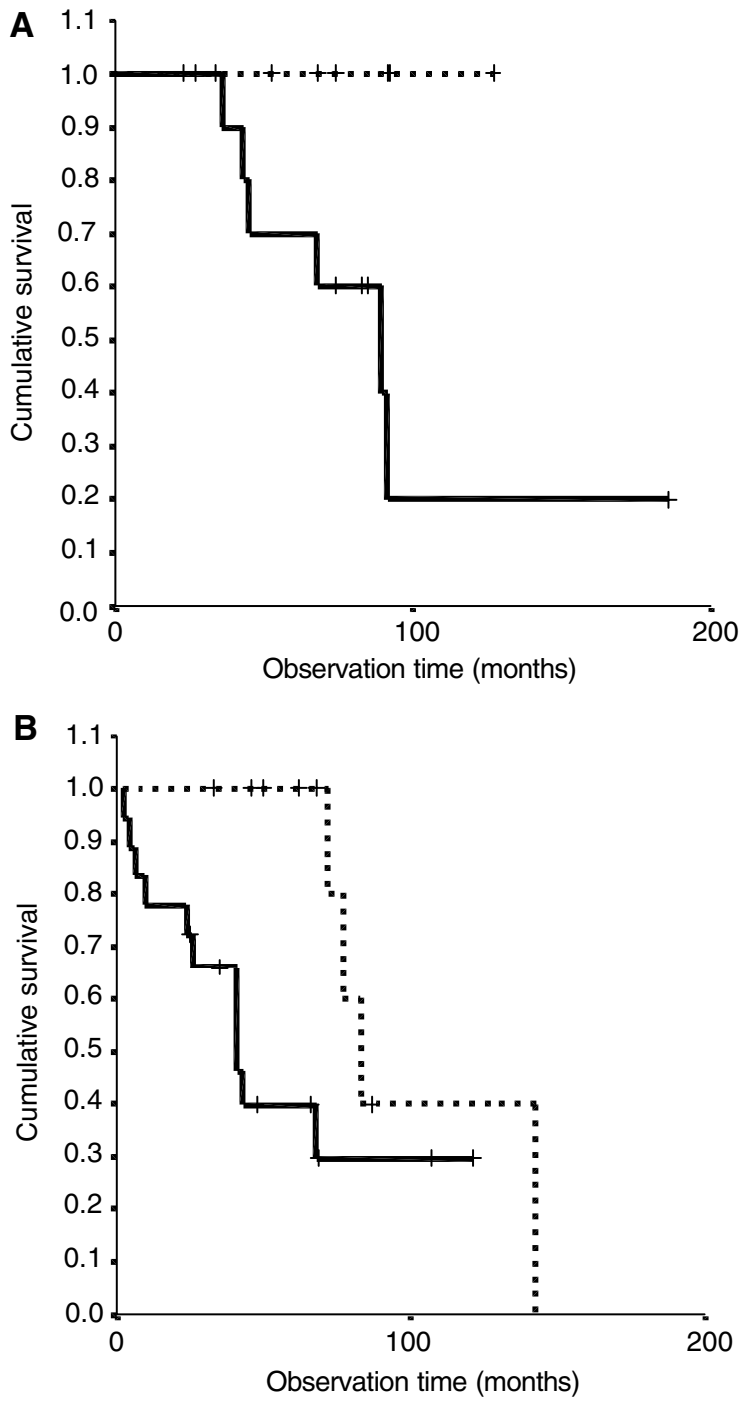

Figure 2 High proliferation (Ki-67) index in A II is associated with shorter survival in $(\mathbf{A})$ patients aged $18-34(P$-value $=0.02)$ and $(\mathbf{B})$ patients $\geqslant 35$ years $(P$-value $=0.03)$. Kaplan-Meier; pooled log-rank test, $P$-value $=0.002 . \cdots \ldots \ldots$ Proliferation index $\leqslant 1 \%(n=18)$. Proliferation index $>1 \%(n=29)$. 

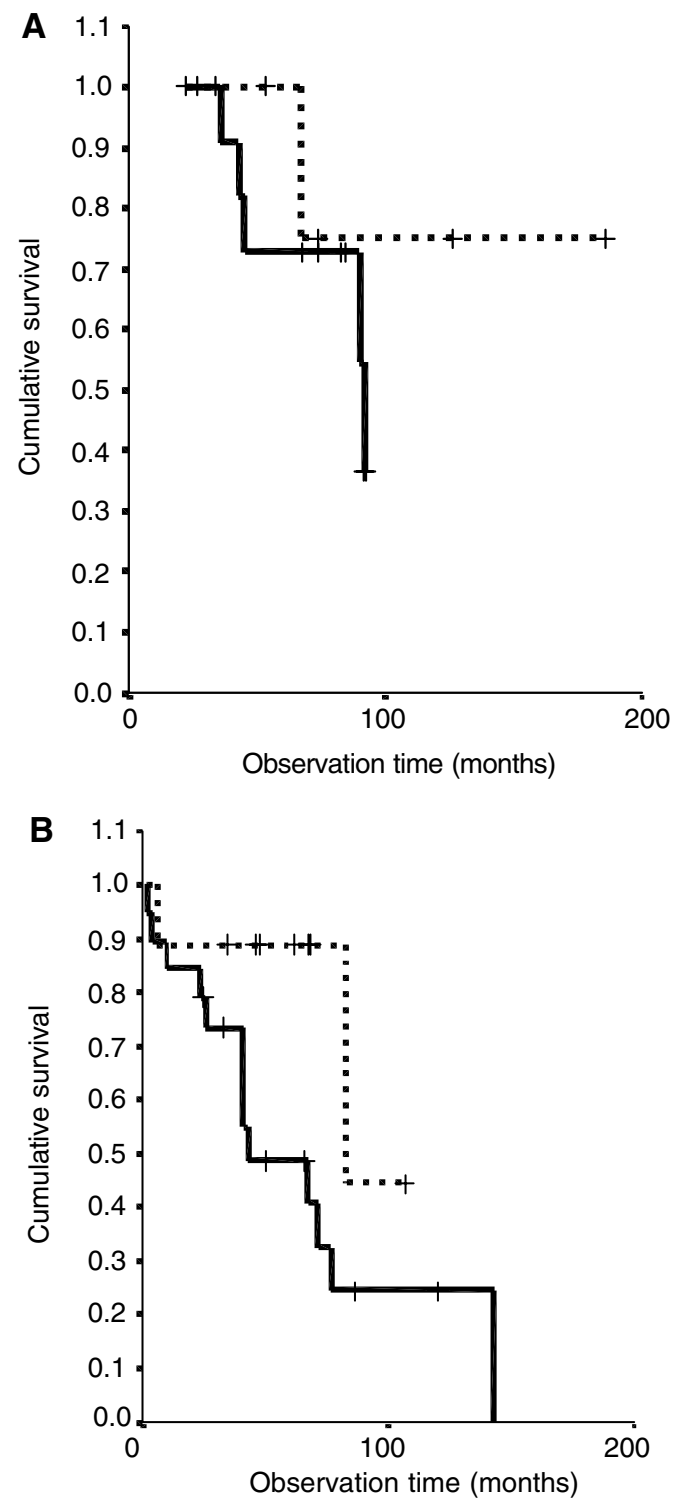

Figure 3 Relation of aneusomy with shorter survival in $(\mathbf{A})$ A II patients aged $18-34(P$-value $=0.36)$ and $(\mathbf{B})$ patients $\geqslant 35$ years $(P$-value $=0.09)$. Kaplan-Meier; pooled log-rank test, $P=0.05 . \ldots \ldots \ldots$ Disomy $(n=15)$. - Aneusomy $(n=32)$.

$\geqslant 35$ years group, the high proliferation index with disomy now correlated with a more favourable course (compare Figures $4 \mathrm{~B}$ to $2 \mathrm{~B}$ ).

Figure 5 illustrates a case of A II, localised in the frontal lobe of a 25-year-old patient with epileptic seizures as the sole manifestation. The proliferation (Ki-67) index was $4.5 \%$ and a high percentage $(35 \%)$ of nuclei with trisomy for chromosome 7 was detected by ISH. Despite the favourable clinical features (young age, no focal deficit), the patient rapidly progressed to astrocytoma grade IV, and the survival interval after histological diagnosis was only 36 months.

\section{DISCUSSION}

A 'wait and see' policy has been propagated for patients under 35 years of age, suffering from epileptic seizures and radiological
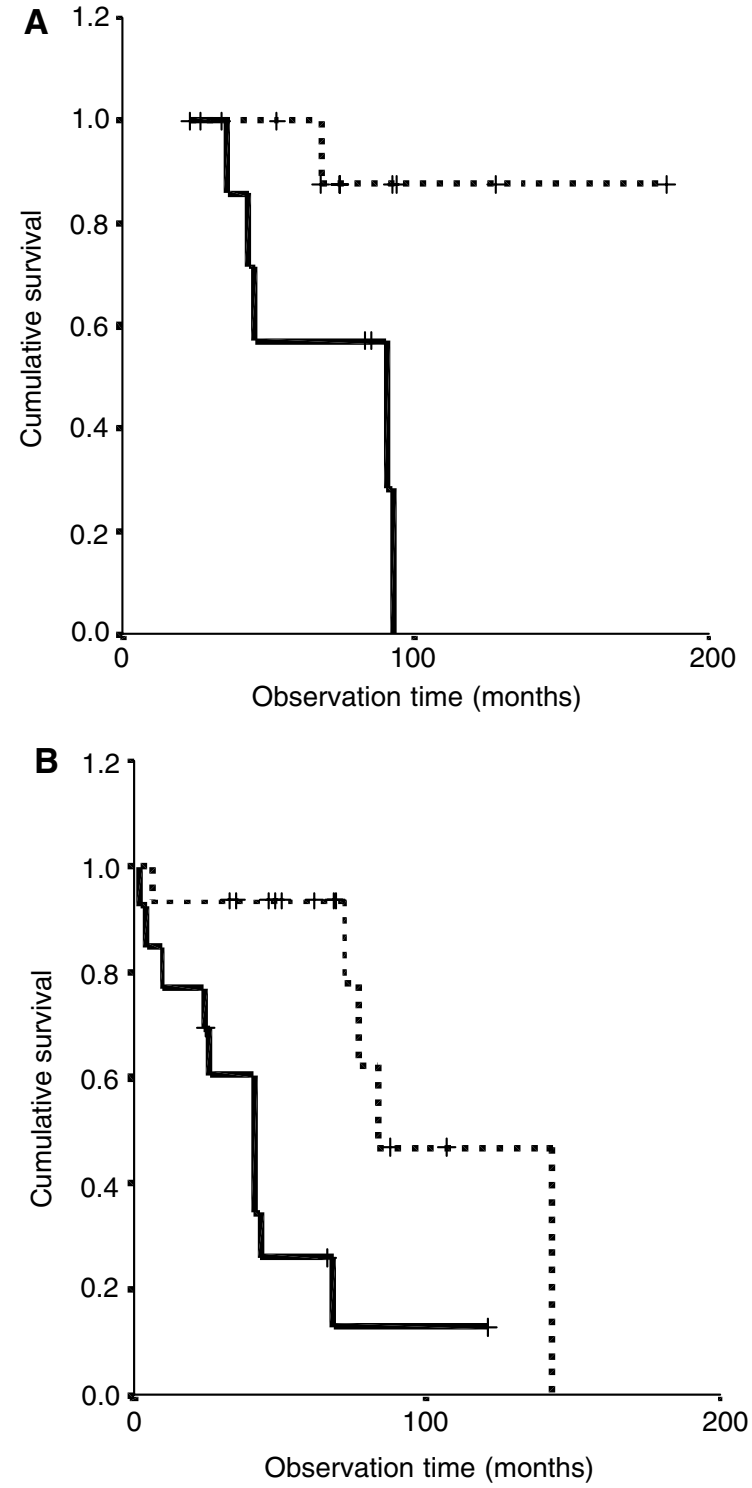

Figure 4 The combination of both high proliferation (Ki-67) index and aneusomy is strongly associated with a shorter survival in A II patients $(\mathbf{A})$ aged $18-34(P=0.01)$ and $(\mathbf{B})$ aged $\geqslant 35$ years $(P=0.001)$. Kaplan Meier; pooled log-rank test, $P<0.0001 . . . \ldots \ldots$ Proliferation index $\leqslant 1 \%$ or Disomy $(n=26)$. — Proliferation index $>1 \%$ and Aneusomy $(n=2 \mathrm{l})$.

suspicion of astrocytoma grade II (A II) (Vecht, 1993). An important argument for not performing a stereotactic biopsy in these patients is that the histological diagnosis of A II does not alter treatment strategy. In the current study, we demonstrate that the detection of a high proliferative activity in combination with chromosomal aberrations identifies a subgroup of young A II patients with a rapid malignant course.

Our study confirms previous studies of A II showing the prognostic value of patient age and symptoms at presentation (Lote et al, 1997; Bauman et al, 1999). In multivariate analyses, only the age of patients at diagnosis remained significantly associated with survival as an independent clinical factor, when comparing patient group under and over 35 years of age. However, when including biological factors describing the proliferative 

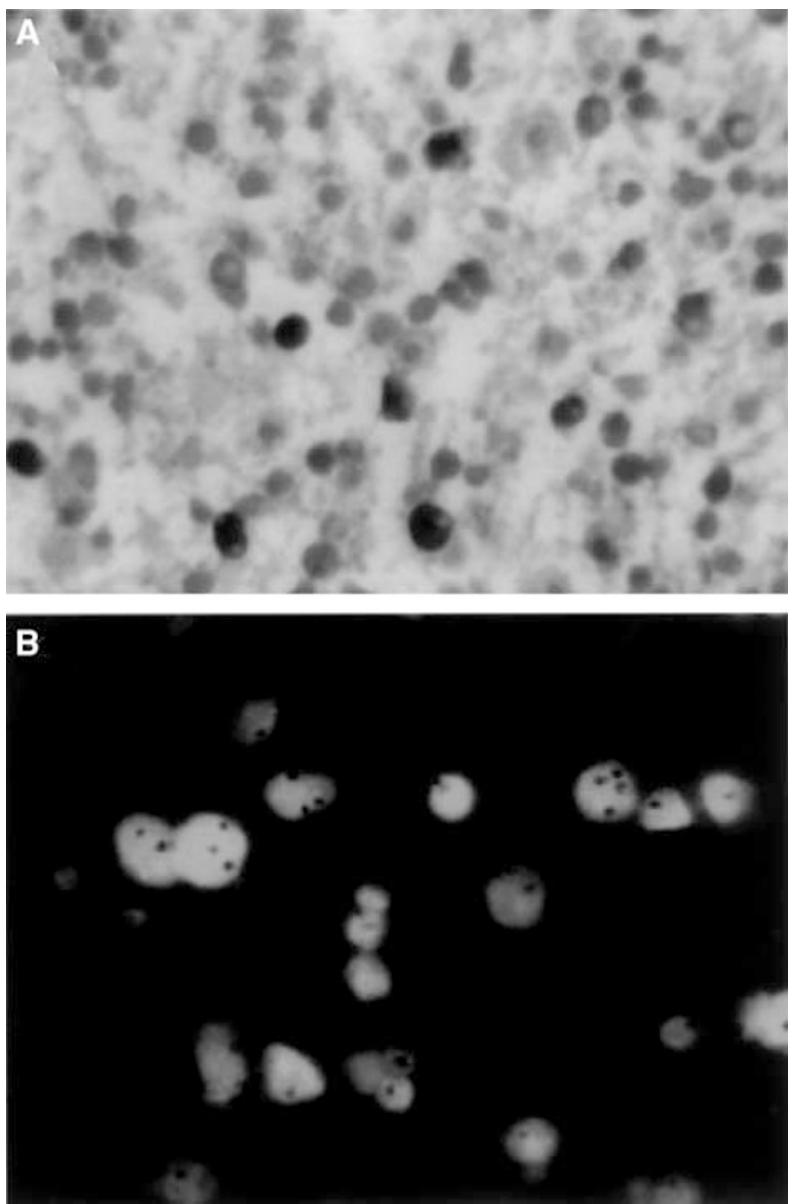

Figure 5 Astocytoma grade II in a patient aged 25 years with a high proliferation (Ki-67) index (A), and frequent nuclei with trisomy for chromosome 7, detected by ISH (B). Counter-staining with DAPI in (B). Magnifications $\times 800$.

capacity and genomic constitution of the lesion, subgroups of patients with a significantly shorter survival could be distinguished within these two separate age groups. In our study, immunostaining for the proliferation marker Ki-67 in over $1 \%$ of tumour cells showed the strongest association with survival of patients with A II. The proliferation (Ki-67) index has been described to increase with the grade of astrocytomas, although overlap between grades exists (Sallinen et al, 1994; Korkolopoulou et al, 1997). The additional value of the $\mathrm{Ki}-67$ labelling protocol in A II was also demonstrated in two recent studies, although in these studies, no stratification for patient age was performed (McKeever et al, 1998; Heesters et al, 1999). We show a significant correlation of proliferation (Ki-67) index with survival for patients under 35 years, separating a group of young patients with a high proliferation index and a prognosis similar to that of patients $>35$ years. Immunolabelling of lesions from patients $\geqslant 35$ years of age identified a subgroup with a low proliferation index, correlating with a somewhat better prognosis. In the multivariate analysis, a proliferation (Ki-67) index $>1 \%$ proved to be a strong independent prognosticator. This corroborates with a bromodeoxyuridine-(BrdU)- proliferation marker analysis of A II that also showed cell cycle activity in $>1 \%$ of tumour cells to be associated with shorter survival (Ito et al, 1994). A possible drawback of the proliferation (Ki-67) index as prognosticator in A II is reflected by the wide variation of cutoff levels (between 2 and 10\%) used in different studies (McKeever et al, 1998; Heesters et al, 1999; Fisher et al, 2002). In our series, the discriminative power of the proliferation (Ki-67) index diminished when using a higher cutoff level than $1 \%$ (data not shown). These differences in cutoff levels, among different studies, may be explained by differences in the immunohistochemical procedures applied, such as the method of antigen retrieval, the immunolabelling protocol, and by differences in the scoring criteria of (clustered) Ki-67positive cells. Therefore, an additional, but independent prognosticator is needed.

The detection of numerical genomic aberrations has such additional prognostic value to the proliferation (Ki-67) index. For astrocytomas of all grades, it appears that certain genetic changes are associated with an unfavourable clinical course. Astrocytomas with chromosomal abnormalities as detected by karyotyping lead to a shorter survival as compared to astrocytomas without these abnormalities (Kimmel et al, 1992). An ISH study showed that monosomy for chromosome 10, harbouring the tumour suppressor gene PTEN/MMAC1, results in shorter survival (Cianciulli et al, 2000). However, in these series, the majority of tumours represented high-grade astrocytoma (grades III and IV). In A II, the most frequently reported genetic aberration is loss or mutation of the p53 gene, which, however, shows no association with clinical course (Kraus et al, 1994; al-Sarraj and Bridges, 1995).

One of the very few additional studies correlating genetic aberrations and clinical course includes a comparative genomic hybridisation (CGH) analysis, which showed that A II with rapid malignant progression exhibit a significantly higher number of chromosomal aberrations as compared to A II with an indolent behaviour (Sallinen et al, 1997). However, the sensitivity of this $\mathrm{CGH}$ technique is relatively low due to contamination with normal/reactive cells, which are often present in A II (Kallioniemi et al, 1994).

In contrast, the ISH procedure is routinely applicable to paraffin-embedded samples of central nervous system tumours (Arnoldus et al, 1992). Our study demonstrates that the detection of chromosomal aberrations by ISH, using a panel of probes for chromosomes 1, 7, and 10, offers an extra independent predictor for survival of patients with A II. After stratification for age, the presence of chromosomal aberrations alone is not significantly associated with shorter survival, which may be caused by the small size of both groups. However, in both age groups, the detection of aneusomy by ISH adds value to the proliferation index, in that increased proliferation in the presence of chromosomal aberrations is associated with a poor prognosis.

A correlation between aneusomy and proliferative activity was demonstrated in astrocytomas of all grades, containing aneusomies for chromosomes 7 and 10, particularly in Ki-67-positive cells (Steilen-Gimbel et al, 1996). This suggests that an accumulation of chromosomal aberrations in proliferating cells plays an important role in the early stages of astrocytoma progression. This also suggests that the combination of both these parameters is therefore very useful in identifying A II with a rapidly malignant clinical course.

Although imaging studies were used as adjunct to histology, A III/IV may also present as nonenhancing lesions (Chamberlain et al, 1988). Therefore, one could argue that in the stereotactic specimen, sampling error from high-grade astrocytomas may have biased the results. This is contradicted, however, by the relatively long median survival of 90 months, also compared to other A II studies (Leighton et al, 1997; McCormack et al, 1992). Another argument against underscoring of the tumours is given by the fact that only one of the biopsy specimens exhibited monosomy 10, which is characteristic at low-grade areas in high-grade astrocytomas (Cheng et al, 1999).

The additional value of genetic and biological parameters to the current histological WHO classification was also seen in the three gemistocytic variants of A II. Previous studies suggest that A II 
with high percentages ( $>60 \%$ ) of gemistocytes, in fact, behave in a more similar manner to A III (Krouwer et al, 1991). Although two of our gemistocytic samples contained lower percentages of gemistocytes, the increased proliferation activity and the presence of aneusomy in all three samples was associated with a relatively short survival (range 41-43 months).

We postulate that identification of subtypes of astrocytomas on the basis of genetic and biological factors has additional prognostic value to the current histological classification. Tissue should be obtained in all patients with A II in order to assess the proliferation activity and, if possible, the presence of trisomy for chromosome 7. In the future, these markers may help in optimising treatment strategy, in particular in young patients with astrocytoma grade II, for whom optimal treatment is now controversial.

\section{ACKNOWLEDGEMENTS}

We thank M Pijls, A Ruland, and J Smeets, Department of Pathology, University Hospital Maastricht, for their technical assistance, and Dr P Koehler, neurologist, and Dr M Nap and Dr P Theunissen, pathologists, Atrium hospital Heerlen, for contributing clinical data and tissue material.

\section{REFERENCES}

al-Sarraj S, Bridges LR (1995) p53 immunoreactivity in astrocytomas and its relationship to survival. Br J Neurosurg 9: $143-149$

Arienti VM, Botturi A, Boiardi A, Broggi G, Collice M, Fariselli L, Zanni D, Botturi M (2001) Adult brain low-grade astrocytomas: survival after surgery and radiotherapy. Neurol Sci 22: 233-238

Arnoldus EP, Wolters LBT, Voormolen JHC, van Duinen SG, Raap AK, van der Ploeg M, Peters ACB (1992) Interphase cytogenetics: a new tool for the study of genetic changes in brain tumors. J Neurosurg 76: 997-1003

Bauman G, Lote K, Larson D, Stalpers L, Leighton C, Fisher B, Wara W, MacDonald D, Stitt L, Cairncross JG (1999) Pretreatment factors predict overall survival for patients with low-grade glioma: a recursive partitioning analysis. Int J Radiat Oncol Biol Phys 45: 923-929

Berger MS, Deliganis AV, Dobbins J, Keles GE (1994) The effect of extent of resection on recurrence in patients with low grade cerebral hemisphere gliomas. Cancer 74: 1784-1791

Chamberlain MC, Murovic JA, Levin VA (1988) Absence of contrast enhancement on CT brain scans of patients with supratentorial malignant gliomas. Neurology 38: 1371-1374

Cheng Y, Ng HK, Ding M, Zhang SF, Pang JC, Lo KW (1999) Molecular analysis of microdissected de novo glioblastomas and paired astrocytic tumors. J Neuropathol Exp Neurol 58: 120-128

Cianciulli AM, Morace E, Coletta AM, Occhipinti E, Gandolfo GM, Leonardo G, Carapella CM (2000) Investigation of genetic alterations associated with development and adverse outcome in patients with astrocytic tumor. J Neurooncol 48: 95-101

Cox D (1972) Regression model and life tables. J R Stat Soc Ser B 34: $187-229$

Fisher BJ, Naumova E, Leighton CC, Naumov GN, Kerklviet N, Fortin D, Macdonald DR, Cairncross JG, Bauman GS, Stitt L (2002) Ki-67: a prognostic factor for low-grade glioma? Int J Radiat Oncol Biol Phys 52: $996-1001$

Heesters MAAM, Koudstaal J, Go KG, Molenaar WM (1999) Analysis of proliferation and apoptosis in brain gliomas: prognostic and clinical value. J Neurooncol 44: $255-266$

Hopman AHN, Ramaekers FCS (1998) Processing and staining of cell and tissue material for interphase cytogenetics. In Current protocols in cytometry, Robinson P (ed). New York: John Wiley \& Sons, Inc (CHAPTER 8.5.1-8.5.2)

Hosmer DW, Lemeshow S (2000) Applied Logistic Regression. New York John Wiley \& Sons

Ito S, Chandler KL, Prados MD, Lamborn K, Wynne J, Malec M, Wilson C, Davis R, Hoshino T (1994) Proliferative potential and prognostic evaluation of low-grade astrocytomas. J Neurooncol 19: 1-9

Kallioniemi OP, Kallioniemi A, Piper J, Isola J, Waldman FM, Gray JW, Pinkel D (1994) Optimizing comparative genomic hybridization for analysis of DNA sequence copy number changes in solid tumors. Genes Chromosomes Cancer 10: $231-243$

Karim ABMF, Afra D, Cornu P, Bleehan N, Schraub S, De Witte O, Darcel F, Stenning S, Pierart M, van Glabbeke M (2002) Randomized trial on the efficacy of radiotherapy for cerebral low-grade glioma in the adult: European Organization for Research and Treatment of Cancer Study 22845 with the Medical Research Council study BRO4: an interim analysis. Int J Radiat Oncol Biol Phys 52: 316-324

Karim ABMF, Maat B, Hatlevoll R, Menten J, Rutten EHJ, Thomas DGT, Mascarenhas F, Horiot JC, Parvinen LM, van Reijn M, Jager JJ, Fabrini MG, van Alphen AM, Hamers HP, Gaspar L, Noordman E, Pierart M, van
Glabbeke M (1996) A randomized trial on dose-response in radiation therapy of low-grade cerebral glioma: European Organization for Research and Treatment of Cancer (EORTC) Study 22844. Int J Radiat Oncol Biol Phys 36: 549-556

Kimmel DW, O'Fallon JR, Scheithauer BW, Kelly PJ, Dewald GW, Jenkins RB (1992) Prognostic value of cytogenetic analysis in human cerebral astrocytomas. Ann Neurol 31: 534-542

Korkolopoulou P, Christodoulou P, Kouzelis K, Hadjiyannakis M, Priftis A, Stamoulis G, Seretis A, Thomas-Tsagli E (1997) MDM2 and p53 expression in gliomas: a multivariate survival analysis including proliferation markers and epidermal growth factor receptor. Br J Cancer 75: $1269-1278$

Kleihues P, Cavenee WK (2000) Pathology and Genetics of Tumors of the Nervous Sytem. IARC press: Lyon

Kraus JA, Bolln C, Wolf HK, Neumann J, Kindermann D, Fimmers R, Forster F, Baumann A, Schlegel U (1994) TP53 alterations and clinical outcome in low grade astrocytomas. Genes Chromosomes Cancer 10: 143-149

Krouwer HG, Davis RL, Silver P, Prados MD (1991) Gemistocytic astrocytomas: a reappraisal. J Neurosurg 74: 399-406

Leighton C, Fisher B, Bauman G, Depiero S, Stitt L, MacDonald D, Cairncross G (1997) Supratentorial low-grade glioma in adults: an analysis of prognostic factors and timing of radiation. J Clin Oncol 15: $1294-1301$

Lote K, Egeland T, Hager B, Stenwig B, Skullerud K, Berg-Johnsen J, StormMathisen I, Hirschberg H (1997) Survival, prognostic factors, and therapeutic efficacy in low-grade glioma: a retrospective study in 379 patients. J Clin Oncol 15: 3129-3140

McCormack BM, Miller DC, Budzilovich GN, Voorhees GJ, Ransohoff J (1992) Treatment and survival of low-grade astrocytoma in adults - 1977 - 1988. Neurosurgery 31: 636-642

McKeever PE, Strawderman MS, Yamini B, Mikhail AA, Blaivas M (1998) MIB-1 proliferation index predicts survival among patients with grade II astrocytoma. J Neuropathol Exp Neurol 57: 931 - 936

Recht LD, Lew R, Smith TW (1992) Suspected low-grade glioma: is deferring treatment safe? Ann Neurol 31: 431-436

Sallinen PK, Haapasalo HK, Visakorpi T, Helen PT, Rantala IS, Isola JJ, Helin HJ (1994) Prognostication of astrocytoma patient survival by Ki-67 (MIB-1), PCNA, and S-phase fraction using archival paraffin-embedded samples. J Pathol 174: 275-282

Sallinen SL, Sallinen P, Haapasalo H, Kononen J, Karhu R, Helen P, Isola J (1997) Accumulation of genetic changes is associated with poor prognosis in grade II astrocytomas. Am J Pathol 151: $1799-1807$

Shaw EG, Arusell R, Scheithauer BW, O'Fallon JR, O'Neill B, Dinapoli R, Nelson D, Earle JD, Jones C, Cascino T, Nichols D, Ivnik R, Hellman R, Curran W, Abrams R (2002) Prospective randomized trial of low- versus high-dose radiation therapy in adults with supratentorial low-grade glioma: initial report of a North Central Cancer Treatment Group/ Radiation Therapy Oncology Group/Eastern Cooperative Oncology Group study. J Clin Oncol 20: 2267-2276

Shaw EG, Daumas-Duport C, Scheithauer BW, Gilbertson DT, O'Fallon JR, Earle JD, Laws ER, Okazaki H (1989) Radiation therapy in the management of low-grade supratentorial astrocytomas. J Neurosurg 70: $853-861$

Steilen-Gimbel H, Henn W, Kolles H, Moringlane JR, Feiden W, Steudel WI, Zang KD (1996) Early proliferation enhancement by monosomy 10 and 
intratumor heterogeneity in malignant human gliomas as revealed by smear preparations from biopsies. Genes Chromosomes Cancer 16: $180-184$

Vecht CJ (1993) Effect of age on treatment decisions in low-grade glioma. J Neurol Neurosurg Psychiatry 56: 1259-1264

Wessels PH, Twijnstra A, Kessels AGH, Krijne-Kubat B, Theunissen PH, Ummelen MIJ, Ramaekers FCS, Hopman AHN (2002) Gain of chromosome 7 as detected by in situ hybridization (ISH) strongly correlates with shorter survival in astrocytoma grade 2. Genes Chromosomes Cancer 33: $279-284$ 